\title{
Translational control of puf operon expression in Rhodobacter sphaeroides 2.4.1
}

\author{
Limin Gong and Samuel Kaplan \\ Author for correspondence: Samuel Kaplan. Tel: +1 713794 1742. Fax: + 17137941782. \\ e-mail : skaplan@utmmg.med.uth.tmc.edu
}

Department of Microbiology and Molecular Genetics, The University of Texas at Houston-Medical School, Houston, TX 77225, USA

\begin{abstract}
The puf operon of Rhodobacter sphaeroides 2.4 .1 encodes the $\beta$ - and $\alpha$-polypeptides of the $B 875$ complex, the $L$ and $M$ polypeptides of the reaction centre and the pufX gene product. A previous report from the authors' laboratory indicated the potential existence of a 20 -codon open reading frame (orfK, now designated pufK) located immediately upstream of the pufB structural gene. It is now demonstrated that pufK is translated in vivo and that the specific levels or nature of the rare codons within pufK affect the expression of pufK. Using a series of pufK-specific mutations, both in trans as lacz translational fusions and incorporated into the genome in single copy, evidence has been obtained that translation initiation through pufK may be essential to translation of pufB. Further, the abundance, quality and distribution of rare codons within pufK may serve to 'gate' the entry of ribosomes at pufB. The data also suggest that translation of pufB is uncoupled from that of pufA, with the latter capable of being produced in excess of the former. It is also revealed that the secondary structure at the $5^{\prime}$ end of the large and small puf transcripts may play a role in mRNA stability and that stability of the small puf transcript is independent of translation.
\end{abstract}

Keywords: $p u f K$, translation, rare codon, gene expression, Rbodobacter

\section{INTRODUCTION}

Rbodobacter sphaeroides 2.4 .1 is a purple nonsulfur photosynthetic bacterium able to grow aerobically, anaerobically in the light, or anaerobically in the dark in the presence of a variety of external electron acceptors such as trimethylamine $N$-oxide (TMAO) or dimethyl sulfoxide (DMSO) (Kiley \& Kaplan, 1988). When growing anaerobically $R$. sphaeroides synthesizes an intracytoplasmic membrane (ICM) system which constitutes the photosynthetic apparatus and possesses the structural components associated with light energy capture, subsequent electron transport, and energy transduction (Kiley \& Kaplan, 1988). Approximately $40-60 \%$ of the total ICM protein is associated with three distinct bacteriochlorophyll a (Bchl) pigment-protein complexes: the photochemical reaction centre (RC), and two functionally and spectrally distinct light-harvesting (LH) complexes, designated B875 (LHI) and B800-850 (LHII) by their absorption maxima (Kiley \& Kaplan, 1988).

Abbreviations: BChl, bacteriochlorophyll a; LH, light harvesting; RC, reaction centre; S-D, Shine-Dalgarno.
The $p u f$ operon encodes the $\beta$ and $\alpha$ polypeptides of the B875 complex, the $\mathrm{L}$ and $\mathrm{M}$ polypeptides of the RC and the pufX (Lee et al., 1989) gene product, which has been suggested to play a critical role in facilitating the interaction between the RC-LHI complex and other components required for light-driven cyclic electron transfer (Farchaus et al., 1992; Barz \& Oesterhelt, 1994; McGlynn et al., 1994). Two major transcripts are produced from the puf operon of $R$. sphaeroides 2.4.1, a small $(0.5 \mathrm{~kb})$ transcript comprised of the coding sequences for puf $B A$, whose $5^{\prime}$ end maps 106 nucleotides $5^{\prime}$ of the $p u f B$ structural gene, and a large $(2.7 \mathrm{~kb})$ transcript corresponding to all five genes ( $p u f B A L M X)$, whose $5^{\prime}$ end maps 80 nucleotides upstream of the start codon of $p u f B$ (Zhu et al., 1986; Lee et al., 1989). In the case of the supposedly closely related bacterium $\mathrm{R}$ bodobacter capsulatus it is reported that there is only a single $5^{\prime}$ end for both the large and small puf transcripts (Belasco et al., 1985), which has led to different interpretations of the available data (Klug et al., 1987). For the most part the ultimate cellular levels of the spectral complexes encoded by these transcripts are related to the levels of the specific transcripts; however, the levels of complexes can rise or fall independent of the cognate mRNA levels. Thus, post- 
transcriptional processes are likely to be involved in establishing the final abundance of each spectral complex (Lee et al., 1989; Sockett et al., 1988; Neidle \& Kaplan, 1992; Gong et al., 1994). One factor is undoubtedly the levels of Bchl (Varga \& Kaplan, 1993); other factors include the level of $p u c$ operon expression and proposed assembly factors which are believed to play a role in determining the levels of spectral complexes via complex formation (Varga \& Kaplan, 1993; Gong et al., 1994). A similar situation has been observed for $R$. capsulatus (Tichy et al., 1989). In addition, mRNA processing has been reported to be involved in puf operon expression in R. capsulatus (Kordes et al., 1994). An additional element which may be involved in establishing the final levels of these spectral complexes is the efficiency of translation of each mRNA species, since the information encoding the $\mathrm{B} 875$ complex is contained within both a large and a small mRNA species, whereas the RC L and M polypeptides are encoded by only the large puf transcript (Zhu et al., 1986).

Previously, our laboratory reported the existence of a DNA sequence containing a 20 -codon open reading frame (orfK) immediately upstream of the $p u f B$ structural gene and terminated by a UAG codon. This ORF herein designated $p u f K$, contains 8 of 20 rare codons in this high$\mathrm{G}+\mathrm{C}$ organism as well as a rare UAG stop codon (Kiley et al., 1987). Therefore, we considered the possible role of pufK. It has been shown that expression of certain downstream genes of an operon is dependent upon the translation of the adjacent upstream gene (Oppenheim \& Yanofsky, 1980; Gold \& Stormo, 1987). The phenomenon, termed translational coupling, has been observed in a number of different operons (Oppenheim \& Yanofsky, 1980; Schümperli et al., 1982; Aksoy et al., 1984; Riggs \& Artz, 1984; Sprengel et al., 1985; Harms et al., 1988). Several molecular models have been described to explain translational coupling, but there are few experimental data to support or contradict any of these theories (Little et al., 1989). In this paper, we demonstrate that $p u f K$ can be translated and we describe features of this translation which may pertain to translational coupling of $p u f B$ to $p u f K$. The data suggest that translation initiation at $p u f K$ plays a role in the translation initiation at $p u f B$ and that ribosome movement through pufK can ultimately affect the final intracellular level of the $\mathrm{B} 875$ spectral complex by limiting the level of B875 $\beta$-polypeptide.

\section{METHODS}

Bacterial strains, plasmids and growth conditions. All bacterial strains and plasmids used in this study are described in Table 1. Escherichia coli strains were grown aerobically on a rotary shaker at $37^{\circ} \mathrm{C}$ using Luria-Bertani (LB) medium. $R$. sphaeroides mutants were derived from wild-type strain 2.4.1, which was originally obtained from W. R. Sistrom, University of Oregon, Portland, OR, USA. R. sphaeroides strains were grown in Sistrom's minimal medium (Sis) (Sistrom, 1962). Cells were grown at $30^{\circ} \mathrm{C}$ either aerobically on a rotary shaker, or photoheterotrophically in completely filled screw-cap tubes or using a sparging mixture with $95 \%(\mathrm{v} / \mathrm{v}) \mathrm{N}_{2}$ and $5 \%(\mathrm{v} / \mathrm{v}) \mathrm{CO}_{2}$ in a temperature-controlled water bath and illuminated by a bank of incandescent lights. When appropriate, the following supplements were added $\left(\mu \mathrm{g} \mathrm{ml}^{-1}\right)$ unless otherwise stated: ampicillin, 50; kanamycin, 25; tetracycline, 12.5 (E. coli) or 1 (R. sphaeroides).

Plasmid construction and DNA manipulation. Standard methods were used for the purification of genomic DNA (Dryden \& Kaplan, 1990), plasmid constructions and transformation of E. coli (Sambrook et al., 1989). Digestions with restriction enzymes were carried out as recommended by the manufacturers.

Conjugative mating. Plasmids to be introduced into $R$. spbaeroides were first transformed into E. coli strain S17-1C. Matings were carried out as described previously (Davis $e t$ al., 1988). Transconjugants were grown aerobically on plates of Sis medium supplemented with appropriate antibiotics.

Mutagenesis. In vitro mutagenesis with synthetic oligonucleotides was performed by using commercially available kits (Amersham and United States Biochemical). ssDNA from pUI1800 was used as template. After annealing, extension and ligation, residual ssDNA template was removed by filtration. The restriction enzyme $N c i$ was used to nick the unprotected non-altered (non-phosphorothioate) strand of the heteroduplex. The mutated DNA molecule was introduced directly into E. coli TG1. The replicative forms of the M13 mutants were purified by standard techniques and the presence of the mutation in the $5^{\prime}$ leader region of $p u f B$ gene was confirmed by DNA sequencing.

Construction of mutations in pufK and formation of pufK: : lacZ fusions. See Fig. 1 for the DNA and derived amino acid sequence for $p u f K$. pUI1837 was constructed by fusing a $1 \cdot 1 \mathrm{~kb} B s p \mathrm{MII}$ fragment carrying the entire R. sphaeroides $2.4 .1 Q$ gene, through the first 19 pufK codons into a DraI fragment containing a 5 'truncated $E$. coli lac $Z$ gene derived from pUI523A*, which is a $\operatorname{Str}^{\mathrm{R}} \mathrm{Spc}^{\mathrm{R}}$ derivative of pUI523A (Tai et

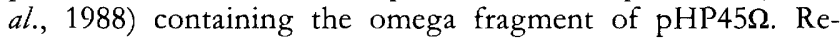
striction analysis was used to show that the fragment was inserted in the correct orientation. pUI1851 was constructed using a $1.32 \mathrm{~kb} \mathrm{RsaI}$ fragment having the same upstream sequence as used for the pufK fusion; it was fused to lac $Z$ after the first 47 codons of $p u f B$ and was inserted at the $S \mathrm{maI}$ site of pUI523A* to obtain pUI1851. Insertion in the correct orientation was confirmed by restriction analysis. The resulting plasmid pUI1851 was subsequently introduced into R. sphaeroides 2.4.1.

See Fig. 2 for a representation of the mutations which were constructed. MAE was constructed using the deoxyoligonucleotide 5'-TGCCT'TACCGTAACGTAACCCACGCCAC CAG-3'. The resulting mutation contains an additional $5 \mathrm{bp}$ (GTAAC) immediately following the seventh codon of $p u f K$ so that translation of part of the pufK sequence occurs in the +1 reading frame from that point on with respect to the normal reading frame of $p u f K$. KLOOP was constructed using the deoxyoligonucleotide 5'-TACCGTAACCCCGGAGTCT'TA CGATC- $3^{\prime}$, which has the sequences from 44 to 24 bp upstream from the $p u f B$ start codon deleted and replaced with CCG. The $\Delta \mathrm{K}$ mutation was made with the deoxyoligonucleotide $5^{\prime}$ GCGGATTAATCGGTCCGGAGGATAG-3', in which 57 nucleotides encompassing nearly all of the pufK gene were deleted. The KSD construction, made with the deoxyoligonucleotide $5^{\prime}$-GATTAATCGTCCATCCATGGTGCCT-3', resulted in the change of the $\mathrm{S}-\mathrm{D}$ sequence preceding $p u f K$ from GGAGGG to TCCATA. Finally, the KSTART mutation was created with the deoxyoligonucleotide 5 'ATCGGGAGG CTTTAAACCTTACCGT-3', where we replaced the potential initiation codon(s) of pufK ATGGTG with T'T'TAAA. 
Translational control in $R$. sphaeroides 2.4 .1

Table 1. Bacterial strains and plasmids

\begin{tabular}{|c|c|c|}
\hline Strain or plasmid & Relevant genotype or phenotype & Source or reference \\
\hline \multicolumn{3}{|l|}{ E. coli } \\
\hline S17-1C & 600: : RP-4 2-Tc: :Mu-Km: :Tn7 hsdR bsdM rec.A thi pro & Simon et al. (1983) \\
\hline TG1 & $\mathrm{K} 12, \Delta($ lac-pro $)$ supE thi hsdD $5 / F^{\prime}$ traD36 pro $A+B+$ lacI lac $Z \Delta \mathrm{M} 15$ & Amersham \\
\hline \multicolumn{3}{|l|}{ R. sphaeroides } \\
\hline 2.4.1 & Wild-type & Van Neil (1944) \\
\hline PUFB1 & 2.4.1 derivative $\left(\mathrm{ORF} Q^{-} \mathrm{Puf}^{-}\right) \mathrm{Km}^{\mathrm{r}}$ & DeHoff et al. (1988) \\
\hline KSTART & 2.4.1 derivative containing KSTART mutation & This study \\
\hline KSD & 2.4.1 derivative containing KSD mutation & This study \\
\hline$\Delta \mathrm{K}$ & 2.4.1 derivative containing $\Delta \mathrm{K}$ mutation & This study \\
\hline KLOOP & 2.4.1 derivative containing KLOOP mutation & This study \\
\hline MAE & 2.4.1 derivative containing MAE mutation & This study \\
\hline \multicolumn{3}{|l|}{ Plasmids } \\
\hline pRK415 & pRK404 derivative with modified polylinker; $T c^{r}$ & Keen et al. (1988) \\
\hline pUCp6.37 & pUC19 derivative containing 14S rRNA gene of R. sphaeroides 2.4 .1 & Dryden \& Kaplan (1990) \\
\hline pUI655 & $\mathrm{pBS} /$ HincII, $0.48 \mathrm{~kb}$ StyI-StyI of pufB $A$ DNA & DeHoff et al. (1988) \\
\hline pUI523A* & $\operatorname{Str}^{R} \operatorname{Spc}^{\mathrm{R}}$ derivative of vector $\mathrm{pUI523 \textrm {A }}$ & Tai et al. (1988) \\
\hline pUI1800 & M13mp18 with Pst $:: K p n \mathrm{I}$ ORFQKpufB $A$ fragment & Gong et al. (1994) \\
\hline pUI1801 & pRK415 with $\operatorname{Spc}^{r} \Omega$ cartridge in HindIII site; $\mathrm{Tc}^{\mathrm{r}} \mathrm{Spc}^{\mathrm{r}}$ & Gong et al. (1994) \\
\hline pUI1837 & pUI523A*/DraI, $1 \cdot 1 \mathrm{~kb}$ BspMII of puf upstream DNA & This study \\
\hline pUI1838 & $\begin{array}{l}\text { pUI523A*/Stul, } 1 \cdot 1 \mathrm{~kb} \text { BspMII of } p u f \text { upstream DNA containing MAE } \\
\text { mutation }\end{array}$ & This study \\
\hline pUI1843 & $\begin{array}{l}\text { pUI523A*/DraI, } 1 \cdot 1 \mathrm{~kb} \text { BspMII of } p u f \text { upstream DNA containing KSTART } \\
\text { mutation }\end{array}$ & This study \\
\hline pUI1849 & $\begin{array}{l}\text { pUI523A*/DraI, } 1 \cdot 1 \mathrm{~kb} \text { BspMII of puf upstream DNA containing KLOOP } \\
\text { mutation }\end{array}$ & This study \\
\hline pUI1851 & pUI523A*/SmaI, $1.3 \mathrm{~kb}$ RsaI of puf DNA & This study \\
\hline pUI1854 & $\begin{array}{l}\text { pUI523A*/DraI, } 1 \cdot 1 \mathrm{~kb} \text { BspMII of puf upstream DNA containing KSD } \\
\text { mutation }\end{array}$ & This study \\
\hline
\end{tabular}

The pufK::lac $Z$ translational fusions for KSD (pUI1854), KSTART (pUI1843), KLOOP (pU11849) and MAE (pUI1838) were identical to pUI1837, except for the changes described and the use of the StuI fragment of pUI523A* in the case of MAE (Figs 1 and 2).

PCR techniques. These were carried out using the GeneAmp PCR reagent kit (Perkin-Elmer Cetus). PCR fragments ( $300 \mathrm{bp}$ ) carrying the KSTART, KSD, $\triangle \mathrm{K}$, KLOOP or MAE mutation, respectively, were amplified from chromosomal DNA using primers LG-PCR1 and LG-PCR2. Primer LG-PCR1 has the sequence $5^{\prime}$-TCGCCGTCATTCTGCTGG-3', corresponding to residues $260-279$ upstream from the start codon of $p u f B$. Primer LG-PCR2 is a 20 -nucleotide complementary-strand sequence from $20 \mathrm{nt}$ to $39 \mathrm{nt}$ downstream from the start codon of $p u f B$ (5'-CGTAAGACCTGTG TAGCCCA-3'). PCR amplification was performed as described previously (Gong et al., 1994). The DNA sequence of all mutations was confirmed at each step in the process of their construction, including the lac $Z$ fusions, and both prior to and following their incorporation into the chromosome in single copy.

DNA sequencing. DNA was sequenced by the dideoxy chaintermination method (Sanger et al., 1977), using the Sequenase kit version 2.1 (US Biochemicals) and $\left[{ }^{35} \mathrm{~S}\right] \mathrm{dATP} \alpha \mathrm{S}$ (Amersham), following the method for double-stranded DNA templates as outlined by the manufacturer. DNA sequence for PCR products was determined by automated sequencing performed at the Core Facility of the Department of Micro- biology and Molecular Genetics in the University of Texas Medical School at Houston with the DyeDeoxy Terminator cycle sequencing kit and a model 373A DNA sequencer (Applied Biosystems).

$\boldsymbol{\beta}$-Galactosidase assays. Cells grown aerobically with $69 \%$ $(\mathrm{v} / \mathrm{v}) \mathrm{N}_{2}, 30 \%(\mathrm{v} / \mathrm{v}) \mathrm{O}_{2}$ and $1 \%(\mathrm{v} / \mathrm{v}) \mathrm{CO}_{2}$ were harvested at

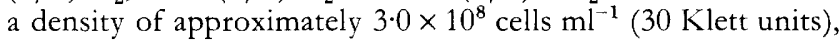
and cells grown photosynthetically using a sparging mixture of $95 \%(\mathrm{v} / \mathrm{v}) \mathrm{N}_{2}$ and $5 \%(\mathrm{v} / \mathrm{v}) \mathrm{CO}_{2}$ at $100 \mathrm{~W} \mathrm{~m}^{-2}$ were harvested at a cell density of approximately $5.0 \times 10^{8}$ (50 Klett units). Cell breakage with a French press, preparation of crude extracts, and $\beta$-galactosidase assays were performed as described previously (Tai et al., 1988). Each assay was performed in duplicate, and each determination was performed at least three times. All determinations were within the linear response range of the assay.

SDSPAGE and Western blotting. For identification and measurement of specific proteins present in cell lysates, the proteins were separated by SDS-PAGE; one half of the gel was stained with Coomassie brilliant blue, and the other half was transferred electrophoretically to nitrocellulose membranes in cooled $25 \mathrm{mM}$ Tris $/ \mathrm{HCl}(\mathrm{pH} 8.3$ ) containing $192 \mathrm{mM}$ glycine and $20 \%(\mathrm{v} / \mathrm{v})$ methanol. Electrophoresis was carried out with a $10-16.5 \%$ linear acrylamide gradient SDS-polyacrylamide gels with $0.5 \% \mathrm{NaCl}$ in the resolving gel to increase the resolution of low-molecular-mass polypeptides (Kiley et al., 1987). The membranes were then soaked in Tris-buffered saline 
(50 mM Tris, $150 \mathrm{mM} \mathrm{NaCl}$, adjusted to $\mathrm{pH} 7 \cdot 4$ with $\mathrm{HCl}$ ) containing $5 \%(\mathrm{w} / \mathrm{v})$ bovine serum albumin to block nonspecific antibody-binding sites, and washed between steps with Tris-buffered saline containing $0.05 \%$ Tween 20 . Membranes were probed with polyclonal antibody $\operatorname{IgG}-\mathrm{B} 875-\alpha$, and the bound antibody was detected using alkaline-phosphataselabelled anti-IgG (Promega). Each estimate of the amount of the B875 $\alpha$-polypeptide was performed three times.

RNA isolation and Northern analysis. R. sphaeroides RNA was isolated by the method described previously (Gong et al., 1994; Neidle \& Kaplan, 1993) on at least three separate samples. Primer extension reactions with avian myeloblastosis virus reverse transcriptase were performed as described previously (Lee et al., 1989). Twenty micrograms of R. sphaeroides RNA was used in the reaction. The sequencing reaction was performed with Sequenase, employing the dideoxy-sequencing method (Sanger et al., 1977) as described above.

Spectrophotometric and protein determinations. The preparation of the cell-free extract from R. sphaeroides, protein determination, and spectral analysis were as described previously (Gong et al., 1994). Each assay for spectral complex abundance was performed no less than six times and the leveis of complex in each sample were determined by the Meinhardt equation (Meinhardt et al., 1985).

Determination of the half-life of the puf-specific transcripts. Total RNA was extracted from $600 \mathrm{ml}$ cultures of midexponential-phase $\left(6 \times 10^{8}\right.$ cells $\left.\mathrm{ml}^{-1}\right)$ photosynthetically growing $\left(100 \mathrm{~W} \mathrm{~m}^{-2}\right) \mathrm{R}$. sphaeroides. Rifampicin was added to the cultures at a final concentration of $200 \mu \mathrm{g} \mathrm{ml}^{-1}$. Portions $(24 \mathrm{ml})$ were removed at various time intervals $(0,5,20,40$ and $60 \mathrm{~min})$ and processed for total RNA. RNA was quantified using a Betascope model 603 Blot Analyzer (Betagen; 14S rRNA was used as the control.

Materials. Restriction endonucleases, T4 DNA ligase, T4 polynucleotide kinase, E. coli DNA polymerase I (Klenow fragment) and proteinase $\mathrm{K}$ were purchased from Promega, Bethesda Research Laboratories, Boehringer Mannheim or New England Biolabs. Synthetic oligonucleotide primers were synthesized at the Core Facility of the Department of Microbiology and Molecular Genetics in the University of Texas Medical School at Houston. Antibiotics and other reagents were reagent grade and were purchased from Sigma.

\section{RESULTS}

\section{Translational efficiency of pufK}

Sequence analysis of the puf operon and investigation of the derived mRNA transcripts established that both the small $(0.5 \mathrm{~kb})$ and the large $(2.7 \mathrm{~kb})$ puf transcripts contain an upstream open reading frame, pufK, encoding 20 amino acids, with its stop codon $1 \mathrm{nt}$ proximal to the ATG of pufB (Kiley et al., 1987). This putative leader peptide coding region is preceded by a good S-D sequence, has an ATG-methionine followed by a GTG valine, and terminates with a rare UAG. The putative pufK S-D sequence is either 10 or $36 \mathrm{nt}$ downstream of the $5^{\prime}$ end of the $2.7 \mathrm{~kb}$ or $0.5 \mathrm{~kb}$ puf transcripts, respectively (Zhu et al., 1986; Gong et al., 1994). Therefore, our first efforts were to clarify whether or not $p u f K$ is translated. We constructed a pufK:: lac $Z$ translational fusion plasmid, pUI1837, which was intro-
Table 2. $\beta$-Galactosidase activity from $R$. sphaeroides 2.4.1 containing the translational fusions indicated

Each assay was performed in duplicate, and each determination was performed at least three times. $\beta$-Galactosidase activities are expressed as $\mu \mathrm{mol} \mathrm{min}^{-1}$ (mg protein) ${ }^{-1}$; the results are means \pm se. Cells grown aerobically with $30 \% \mathrm{O}_{2}, 69 \% \mathrm{~N}_{2}$ and $1 \% \mathrm{CO}_{2}$ were harvested at approximately $3 \times 10^{8}$ cells $\mathrm{ml}^{-1}$. Cells grown photosynthetically with $95 \% \mathrm{~N}_{2}$ and $5 \% \mathrm{CO}_{2}$ at $100 \mathrm{~W} \mathrm{~m}^{-2}$ were harvested at approximately $5 \times 10^{8}$ cells $\mathrm{ml}^{-1}$.

\begin{tabular}{|c|c|c|}
\hline Translational fusion & Aerobic & Photosynthetic \\
\hline pUI523A* & $5 \cdot 8 \pm 0 \cdot 5$ & $7 \cdot 0 \pm 0 \cdot 5$ \\
\hline $\begin{array}{l}\text { 2.4.1 pufK: : lac } Z \\
(\text { pUI1837) }\end{array}$ & $39 \cdot 5 \pm 0 \cdot 5$ & $75 \cdot 5 \pm 0 \cdot 5$ \\
\hline $\begin{array}{l}\text { KSTART pufK: : lac } Z \\
\text { (pUI1843) }\end{array}$ & $6 \cdot 6 \pm 0.5$ & $10 \cdot 3 \pm 0 \cdot 5$ \\
\hline $\begin{array}{l}\text { KSD pufK: : lacZ } \\
\text { (pUI1854) }\end{array}$ & $8 \cdot 2 \pm 0.5$ & $17 \cdot 7 \pm 0 \cdot 5$ \\
\hline $\begin{array}{l}\text { MAE pufK: : lac } Z \\
\text { (pUI1838) }\end{array}$ & $382 \cdot 0 \pm 10 \cdot 0$ & $801.5 \pm 76.5$ \\
\hline $\begin{array}{l}\text { KLOOP pufK: : lac } Z \\
\text { (pUI1849) }\end{array}$ & $6.7 \pm 0.5$ & $11.4 \pm 0.6$ \\
\hline $\begin{array}{l}\text { 2.4.1 pufB: : lac } Z \\
\text { (pUI1851) }\end{array}$ & $435 \cdot 4 \pm 27 \cdot 0$ & $927 \cdot 7 \pm 79 \cdot 0$ \\
\hline
\end{tabular}

duced into $R$. sphaeroides 2.4 .1 and $\beta$-galactosidase activity was measured from cells grown either aerobically or photosynthetically at an incident light intensity of $100 \mathrm{~W} \mathrm{~m}^{-2}$.

As can be seen from Table 2, the expression of the translational fusion of lac $Z$ to $p u f K$ was substantially higher either aerobically or photosynthetically than background expression from lac $Z$ alone. Further, the level of expression increased over twofold when cells were grown under high-light photosynthetic conditions as opposed to aerobic growth. This fold-increase is approximately what was to be anticipated from earlier results (Zhu et al., 1986) using high-light-grown cells. These results indicate that $p u f K$ can be translated and that expression is increased anaerobically, i.e. anaerobic control operates at the level of $p u f K$. To addres the question as to the level of expression of $p u f K$ in the context of the $p u f$ operon we compared the $\beta$-galactosidase activities obtained above to those obtained using a $p u f B::$ lac $Z$ translational fusion plasmid, pUI1851, in which the lac $Z$ gene is fused downstream of the $p u f K$ fusion. $\beta$-Galactosidase activities expressed from this $p u f B$ : : lac $Z$ fusion plasmid were approximately 10 -fold higher than the $p u f K$ fusion under both growth conditions (Table 2). Further, the foldincrease in expression of lac $Z$ under photosynthetic versus aerobic conditions was similar to that observed for the $p u f K$ fusion. One interpretation of these data is that translation initiation through $p u f B$ appears to be independent of translation initiation through $p u f K$, although this does not explain why translation of $p u f B$ is 10 fold higher than translation of $p u f K$. 
(a)

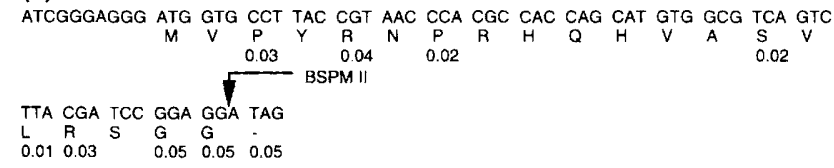

(b)

ATCGGGAGGG ATG GTG CCT TAC CGT AAC GTA ACC CAC GCC ACC AGC ATG TGG CGT

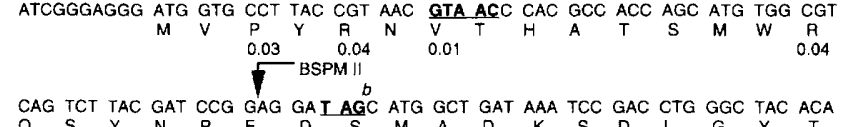

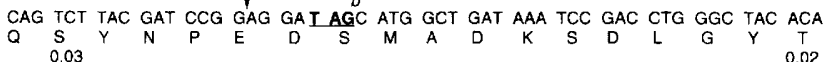

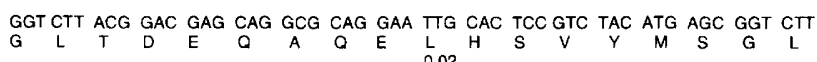
TGG CTG TTC AGC GCG GIC GCG ATC GTC GCT CAC CTC GCT GTG TAC ATC TGG CGT

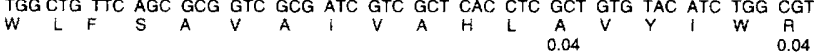
CCG TGG TTC TGA

(c)

(c) † BSPMII

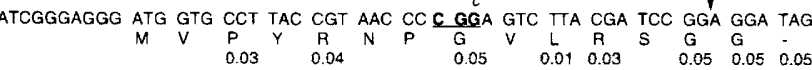

Fig. 1. Nucleotide and derived amino acid sequence of the pufK gene from $R$. sphaeroides 2.4.1 (a), MAE (b) and KLOOP (c). The top line in each part of the figure shows the DNA sequence. The middle line shows the predicted amino acid sequence. The bottom line indicates the frequency of rare codons, which was collected from data published prior to 1994 The following features are indicated by bold underlined characters: $a$, Five nucleotides, GTAAC, which were inserted into the pufK coding region and resulted in frameshifting; $b$, the stop codon for normal PufK; $c$, the site at which 21 nucleotides were deleted and replaced with three nucleotides, CGG.

\section{Rare codons and their effect on the level of pufK translation}

Nucleotide sequence analysis reveals that nine of the 20 pufK codons are amongst those that are rarely used in $R$. sphaeroides 2.4.1 (Fig. 1a). pufK not only contains the rarely used UAG stop codon but also other rare codons. To test whether these codons can affect $p u f K$ expression, we constructed, by site-directed mutagenesis, two mutations within $p u f K$ which alter the relative occurrence of these codons. These altered oligonucleotides were then used to construct translational fusion plasmids as described above in order to test for their expression. As pointed out in Methods, all mutations were confirmed following PCR and DNA sequencing of the PCR product at each step in the construction.

Whereas $p u f K$ contains $43 \%$ rare codons, the pufK frameshift fused to lac $Z$ and designated MAE has only $25 \%$ rarely used codons (Fig. $1 \mathrm{~b}$ ). A second mutation, KLOOP (Fig. 1c), resulted in the deletion of a potential stem-loop structure within pufK containing six of the more commonly used codons. The mutated pufK in KLOOP is translated in its original reading frame, but the frequency of rare codon usage was increased from $43 \%$ to $53 \%$ (Fig. 1c) and the size of the peptide is reduced to 14 amino acids. The $p u f K$ : : lac $Z$ translational fusion plasmids pUI1838 and pUI1849, containing MAE and KLOOP respectively, were constructed and introduced into $R$. sphaeroides 2.4.1. As can be seen in Table 2, $\beta$-galactosidase activity expressed from pUI1838 carrying the MAE mutation when measured from cells grown either aerobically or photosynthetically was approximately 10 - or 13 fold higher, respectively, than that from the corresponding normal $p u f K$ : : lac $Z$ fusion, and was equivalent to that from the pufB: : lac $Z$ fusion. In contrast, the $\beta$-galactosidase activities expressed from pUI1849 containing the KLOOP mutation were near background values. These data suggest that either the use of rare codons or their absolute number and distribution have an effect on the rate of $p u f K$ translation although other interpretations are possible, e.g. the specific codons themselves regardless of the frequency of their usage.

\section{Effect of pufK on expression of pufB and pufA}

Translationally coupled genes are often separated by intercistronic regions which are 3 bases or less (Harms et al., 1988). The speculation is that the short distance between the genes involved is essential for efficient translational coupling (Oppenheim \& Yanofsky, 1980). We have shown previously that the $p u f K$ translation stop codon and $p u f B$ start codon are separated by 1 base, UAG$\mathrm{C}$-AUG. This feature suggested that the two genes may be translationally coupled. However, the data described above suggested that $p u f B$ may be translated independently of $p u f K$. The potential role of $p u f K$ was further highlighted by relating the expression of $p u f K$ to the expression of the puf operon. It was therefore of interest to examine the effects of changing the translational activity of $p u f K$ on the expression of both $p u f B$ and $p u f A$. In order to perform such a series of experiments, we used two different strategies. The expression of $p u f K$ was measured through the construction of lac $Z$ fusions in trans as described above, whereas the expression of $p u f B$ was measured in single copy within the chromosomal context in which it is normally found, in particular with an altered upsteam pufK. DNA sequences usually regarded as being important determinants of translation initiation efficiency are the highly conserved $\mathrm{S}-\mathrm{D}$ sequence and the translational start codon. The approach we used therefore was to create mutations which either altered the $\mathrm{S}-\mathrm{D}$ sequence or changed the initiation codon of pufK (KSTART), or finally we deleted most of the $p u f K$ sequence by sitedirected mutagenesis $(\Delta \mathrm{K})$. Fig. 2 illustrates the mutations which were constructed for this purpose. We then analysed the effect of each mutation on expression of $p u f K$ using lac $Z$ translational fusions in trans as described above. Under aerobic growth conditions both KSD and KSTART gave $\beta$-galactosidase activities near background and under photosynthetic conditions the lac $Z$ levels were only marginally higher than background (Table 2 ). These results demonstrate that both the $\mathrm{S}-\mathrm{D}$ sequence and translational start codon(s) are required for translational expression of $p u f K$ and thus further support the premise that $p u f K$ is translated in situ.

In order to ascertain the effect of the mutations on $p u f B$ expression, each mutation was crossed into the chromosome in single copy by methods previously described (DeHoff et al., 1988; Gong et al., 1994). The structure of 


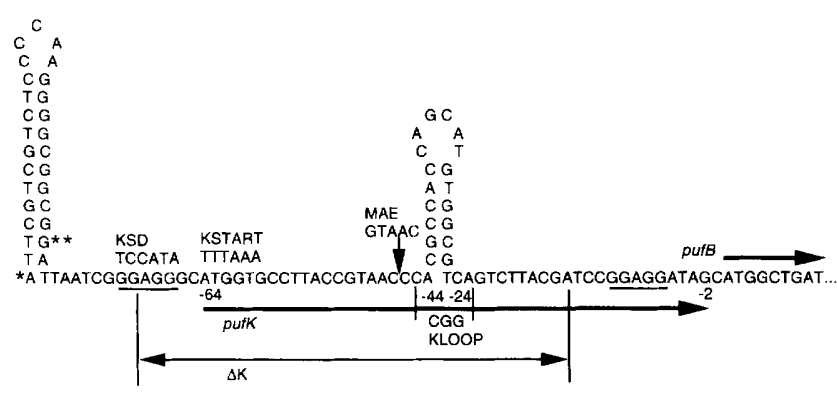

Fig. 2. Sequence and locations of the pufK mutations of $R$. sphaeroides 2.4.1 used in this study. The peptide derived from pufK starts at position -64 and ends at -2 upstream of the pufB start codon. In KSTART, ATGGTG is changed to TTTAAA; in KSD, GGAGGG is changed to TCCATA; KLOOP has a deletion of -24 to -44 upstream from the pufB start codon; $\Delta K$ has a deletion from -23 to -66 upstream of the pufB start codon; in MAE, GTAAC was inserted between -46 and -47 , which resulted in a +1 frameshift. The initiation sites for the small $\left(0.5 \mathrm{~kb} ;{ }^{*}\right)$ and large $\left(2.7 \mathrm{~kb} ;{ }^{*}\right)$ puf transcripts are located at -106 and -80 upstream from the pufB start codon, respectively.

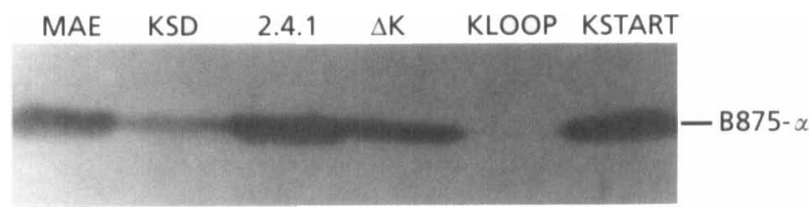

Fig. 3. Western immunoblot analysis, with antibody raised against the B875 $\alpha$-polypeptide (B875- $\alpha$ ), of a $5 \mu \mathrm{g}$ portion of membrane protein fractions from photosynthetically grown $R$. sphaeroides 2.4 .1 and mutants. Proteins were separated by SDSPAGE and transferred electrophoretically to nitrocellulose membranes. The membranes were probed with polyclonal antibody IgG-B875- $\alpha$, and the bound antibody was detected by using alkaline-phosphatase-labelled anti-lgG.

each mutation was confirmed as described (Gong et al., 1994, and data not shown) by DNA sequence analysis of PCR products derived from chromosomal DNA of each of the mutant strains. The construction of the series of puf $K$-specific mutations in R. sphaeroides in single copy in the chromosome allowed us to determine how the apparent translation of $p u f K$ affects the expression of $p u f B$ and $p u f A$ by measurement of the level of the B875 complex and of the $p u f A$ gene product directly by Western immunoblot analysis (Fig. 3). Membrane proteins from photosynthetically grown $R$. sphaeroides 2.4 .1 and the mutant strains (incident light intensity $100 \mathrm{~W} \mathrm{~m}^{-2}$ ) were separated by SDS-PAGE, transferred to nitrocellulose, and reacted with an antibody specific for B875 $\alpha$ polypeptide, as described in Methods. Mutants KSTART and MAE gave levels of the $\alpha$-polypeptide close to that observed for wild-type 2.4.1 (see Table 3). Mutant KLOOP resulted in the apparent absence of the $\alpha$ polypeptide. Between these extremes, mutants $\Delta \mathrm{K}$ and KSD gave intermediate levels of the $\alpha$-polypeptide (Table 3).

\section{Phenotype analysis of pufK mutations}

Fig. 4 shows the absorption spectra obtained from the membrane fractions of wild-type 2.4.1 and all the mutants. Both B800-850 and B875 pigment-protein complexes can be detected in the membranes of R. sphaeroides 2.4 .1 when grown photosynthetically at $100 \mathrm{~W} \mathrm{~m}^{-2}$ (Fig. 4). The absorption coefficients given by Meinhardt et al. (1985) were employed to calculate the levels of the individual spectral complexes in the wild-type and the mutants (Table 3). Each of the mutant determinations was performed at least six times. Using the equation of Meinhardt et al. (1985) we can assess the levels of each LH complex in the presence of the other regardless of how much or how little of either is present. Mutants KSD and $\Delta \mathrm{K}$ contained approximately $4.0 \%$ of the wild-type level of $\mathrm{B} 875$, whereas the amount of B800-850 in both these mutant strains was approximately twice that of the wildtype (Table 3). The level of B875 in KSTART was decreased by approximately $44 \%$ compared with that in the wild-type, whereas the amount of B875 in MAE was approximately $10 \%$ higher than for the wild-type. KLOOP contained no detectable B875. However, the levels of B800-850 in each of these mutant strains increased or decreased in a manner that appeared to be compensatory with regard to the levels of B875 (Table 3). This may reflect the availability of $B c h l$, which we have suggested to be limiting with regard to spectral complex formation (Varga \& Kaplan, 1993).

When grown photosynthetically at an incident light intensity of $100 \mathrm{~W} \mathrm{~m}^{-2}$, strains KSTART, KSD, $\Delta \mathrm{K}$ and MAE had essentially the same growth rate as that of wildtype 2.4.1. However, KLOOP had a doubling time of $5.5 \mathrm{~h}$; although slower than wild-type, the growth rate of KLOOP is appreciable. The lower growth rate of KLOOP is presumably due to the lack of B875 complex. These results support earlier work that the B875 complex is an important intermediate between the B800-850 complex and the RC (Meinhardt et al., 1985; Hess et al., 1993; Gong et al., 1994), and we invariably observe that as long as any B875 complex is present, growth rates at high light intensities are normal.

\section{Northern hybridization analysis}

There are several possible explanations for the above results (Table 3, Fig. 3), one of which depends upon the levels of $p u f$-specific mRNAs. To determine whether the altered levels of B875 spectral complex in the mutant strains were the result of some failure to produce a specific puf-operon-encoded transcript, total RNA was extracted from cells grown photosynthetically at $100 \mathrm{~W} \mathrm{~m}^{-2}$ and used in Northern blot analysis. RNA from each strain was hybridized with puc- and puf-specific RNA probes. To make certain that approximately equal amounts of total RNA were present on each filter, the level of $14 \mathrm{~S}$ rRNA in each sample was measured by using a radiolabelled HindIII and Pst I fragment of plasmid pUCp6.37 as a probe to hybridize to each of the Northern blots. This $400 \mathrm{bp}$ fragment contains the $14 \mathrm{~S}$ rRNA sequence of $R$. sphaeroides 2.4.1 (Dryden \& Kaplan, 1990). 
Translational control in R. sphaeroides 2.4 .1

Table 3. Growth rates, specific Bchl content, and cellular levels of puc- and puf-specific transcripts in $R$. sphaeroids 2.4.1 and mutants

\begin{tabular}{|c|c|c|c|c|c|c|c|c|}
\hline \multirow[t]{2}{*}{ Strain } & \multirow{2}{*}{$\begin{array}{l}\text { Generation } \\
\text { time }(\mathrm{h}) \text { at } \\
100 \mathrm{~W} \mathrm{~m}^{-2}\end{array}$} & \multicolumn{2}{|c|}{ Amount of Bchl in* } & \multirow{2}{*}{$\begin{array}{c}p u c \\
\text { transcript } \nmid \\
(0.5 \mathrm{~kb})\end{array}$} & \multicolumn{3}{|c|}{ puf transcripts $\dagger$} & \multirow{2}{*}{$\begin{array}{c}B 875 \\
\alpha \text {-polypeptide } \\
\text { ( } \% \text { of } \\
\text { wild-type) }\end{array}$} \\
\hline & & B875 & B800-850 & & $2 \cdot 7 \mathrm{~kb}(\mathrm{~L})$ & $0.5 \mathrm{~kb}(\mathrm{~S})$ & $\mathbf{S} / \mathbf{L}$ & \\
\hline 2.4 .1 & $3 \cdot 1 \pm 0 \cdot 5$ & $7 \cdot 5 \pm 0 \cdot 3$ & $4 \cdot 5 \pm 0 \cdot 4$ & $100 \pm 0$ & $100 \pm 0$ & $100 \pm 0$ & $6 \cdot 0 \pm 0 \cdot 1$ & 100 \\
\hline KSTART & $3 \cdot 2 \pm 0 \cdot 5$ & $4 \cdot 2 \pm 0 \cdot 3$ & $5 \cdot 4 \pm 0.5$ & $98 \pm 2$ & $96 \pm 2$ & $70 \pm 2$ & $4 \cdot 6 \pm 0 \cdot 1$ & 90 \\
\hline $\mathrm{KSD}$ & $3.3 \pm 0.5$ & $0 \cdot 28 \pm 0 \cdot 1$ & $8.9 \pm 0.5$ & $105 \pm 5$ & $98 \pm 2$ & $87 \pm 2$ & $5 \cdot 3 \pm 0 \cdot 1$ & 30 \\
\hline$\Delta \mathrm{K}$ & $3 \cdot 2 \pm 0.5$ & $0 \cdot 31 \pm 0 \cdot 1$ & $8.6 \pm 0.3$ & $104 \pm 5$ & $50 \pm 2$ & $20 \pm 2$ & $2 \cdot 4 \pm 0 \cdot 1$ & 50 \\
\hline KLOOP & $5.5 \pm 0.5$ & 0 & $16 \cdot 4 \pm 0.5$ & $180 \pm 5$ & $40 \pm 2$ & $45 \pm 2$ & $6 \cdot 7 \pm 0 \cdot 1$ & $<1$ \\
\hline MAE & $3 \cdot 2 \pm 0 \cdot 5$ & $8 \cdot 2 \pm 0 \cdot 2$ & $3 \cdot 8 \pm 0 \cdot 3$ & $95 \pm 2$ & $110 \pm 2$ & $95 \pm 2$ & $5 \cdot 2 \pm 0 \cdot 1$ & 110 \\
\hline
\end{tabular}

* Determined from the absorption coefficient $\varepsilon_{878-820}=73 \mathrm{mM}^{-1} \mathrm{~cm}^{-1}$ for the B875 complex normalized for 2 mol of Bchl per complex. Similarly, the amount of B800-850 Bchl was calculated by the $A_{\mathbf{9 0 0} 849}$, using $\varepsilon=96 \mathrm{mM}^{-1} \mathrm{~cm}^{-1}$, normalized for 3 mol of Bchl. The results are expressed as nmol spectral complex per mg crude membrane protein, and are means $\pm \mathrm{SE}$.

+ Cells were grown at $100 \mathrm{~W} \mathrm{~m}^{-2}$, and the levels of $p u f$ - and puc-specific transcripts were normalized to those of strain $2.4 .1 \mathrm{using}$ rRNA as the standard. The results are means $\pm \mathrm{sE}$.

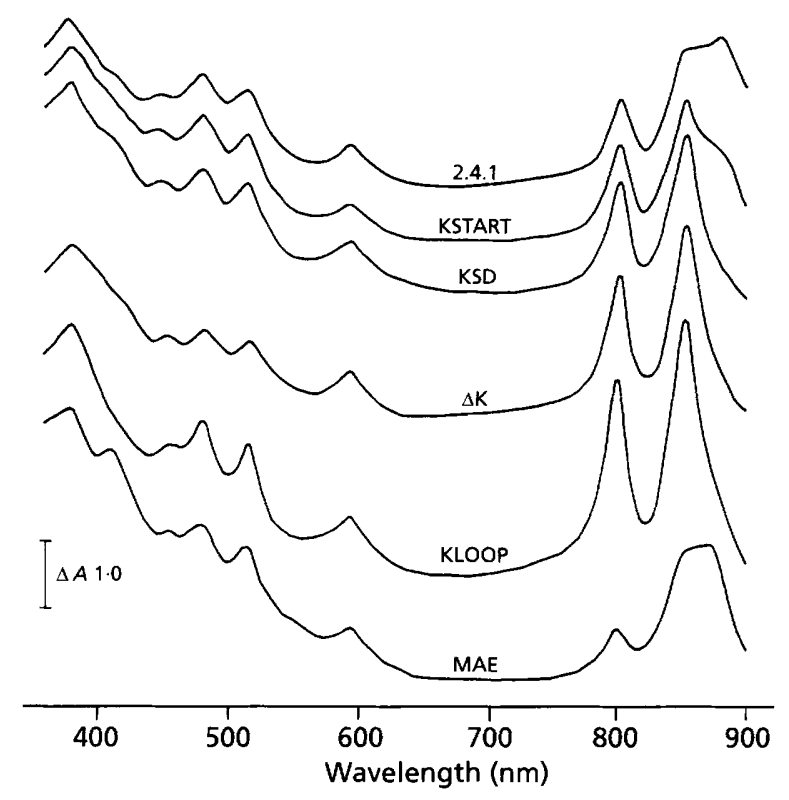

Fig. 4. Absorption spectra of crude cell-free lysates obtained from $R$. sphaeroides 2.4 .1 and mutants grown photosynthetically at $100 \mathrm{~W} \mathrm{~m}^{-2}$. Samples of equal protein concentration $\left(1 \mathrm{mg} \mathrm{ml}^{-1}\right)$ were examined as described in Methods.

Two transcripts, of approximately $0.5 \mathrm{~kb}$ and $2 \cdot 7 \mathrm{~kb}$, were identified when total RNA isolated from 2.4 .1 and the mutants was probed with a riboprobe made as a runoff transcript to a $480 \mathrm{bp} S t y \mathrm{I}$ fragment of $\mathrm{R}$. sphaeroides 2.4 .1 DNA carrying the $p u f B$ and $p u f A$ genes (Gong et al., 1994). The data from the Northern hybridization analysis are summarized in Table 3 . The ratio between the small and large transcript for 2.4 .1 was approximately $6: 1$. The levels of the small transcript derived from KSD and KSTART were $13 \%$ and $30 \%$ lower than that of the wild-type, respectively, whereas the levels of the large transcripts were essentially the same as that of the wildtype. This uncoupling of the relative abundance between large and small transcripts has been discussed previously (Gong et al., 1994) and will not be considered further here, but it could reflect the importance of translation through $p u f K$ in either termination or read-through after $p u f A$. The amount of the large transcript in MAE was increased by $10 \%$ relative to the wild-type, whereas the level of the small transcript was essentially the same as that of the wild-type. $\Delta \mathrm{K}$ showed the most severe alterations in both the large and small transcripts, with an approximately $80 \%$ reduction in the latter. In the case of KLOOP, the amount of small and large puf transcripts decreased approximately $60 \%$ compared with those of the wild-type (Table 3 ). In all cases both large and small puf-specific transcripts were produced, and were produced in sufficient quantity to give rise to appreciable levels of B875 complex. Thus, the presence of rare codons and their effect on translation through $p u f K$ could be analogous to the translational attenuation observed in the regulation of macrolide antibiotic resistance (Horinouchi \& Weisblum, 1980; Dubnau, 1984).

The RNAs from 2.4.1 and the pufK mutants were also probed with an RNA probe made as a runoff transcript to a 534 bp XmaIII fragment of $R$. sphaeroides DNA encoding the LHII $\alpha$ - and $\beta$-polypeptides (the puc operon). All strains tested, except for KLOOP, which had an $80 \%$ increase in the small puc transcript, showed similar amounts of the small puc transcript (Table 3) as did the wild-type. Often when no B875 complex is produced, the levels of puc-specific transcript rise accordingly, as may be reflected in the level of B800-850 complex (Sockett et al., 1988).

The $5^{\prime}$ ends of the large and small puf transcripts in 2.4.1 and in all of the mutants were confirmed by primer extension analysis (data not shown), suggesting that the alteration (either deletion or substitution) in the DNA sequence downstream from the transcriptional start point 


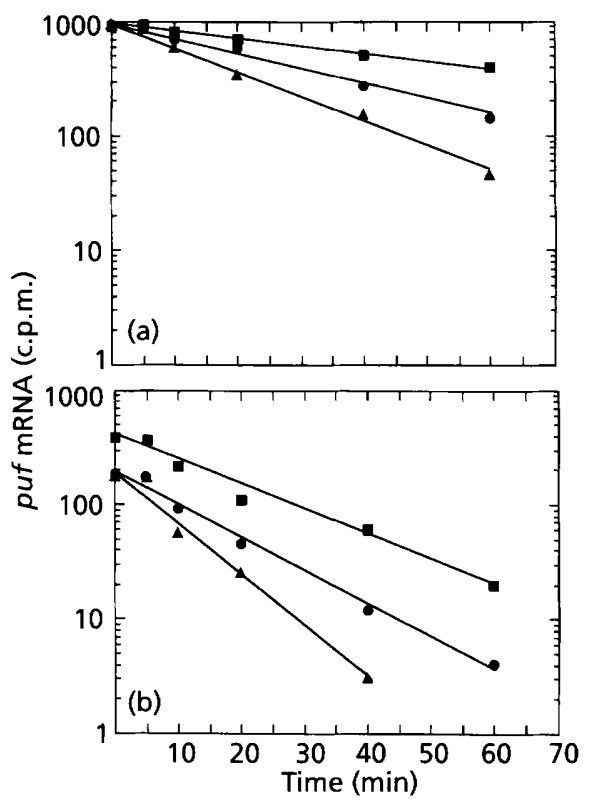

Fig. 5. Stability of puf-specific mRNAs in $R$. sphaeroides 2.4.1, $\triangle \mathrm{K}$ and $\mathrm{KLOOP}$ grown at a light intensity of $100 \mathrm{~W} \mathrm{~m}^{-2}$. The amounts of puf-specific mRNAs from 2.4.1(@), $\Delta \mathrm{K}(\boldsymbol{\square})$ and KLOOP $(\boldsymbol{\Delta})$ after the addition of rifampicin are shown on semilogarithmic plots: (a) the $0.5 \mathrm{~kb}$ transcript; (b) the $2.7 \mathrm{~kb}$ transcript. The amounts of puf-specific mRNAs present were determined by Northern hybridization analysis as described in Methods. The puf transcripts were hybridized with the $[\alpha$ 32P]CTP-labelled pufBA-specific RNA probe. The amount of probe hybridized was determined by a Betascope model 603 Blot Analyzer.

for the puf transcripts had no effect on the location of transcription initiation. As expected, some transcripts were smaller than the corresponding transcripts of the wild-type due to deletions within $p u f K$, while MAE was larger due to the presence of additional nucleotides. The fact that both the large and small transcripts are affected similarly further confirms the coding capacity of each transcript in the pufK region.

\section{Determination of puf transcript stability}

The decay of each puf-specific mRNA was determined from RNA isolated from photosynthetically growing $R$. sphaeroides 2.4 .1 and each pufK-specific mutation. The halflives of both the small and large puf transcripts were determined by Northern hybridization analysis with the puf $B A$-specific probe. The decay values for KSTART, $\mathrm{KSD}$ and MAE were identical to those obtained from 2.4.1 (data not shown). The half-life determinations for each transcript in 2.4.1, $\Delta \mathrm{K}$ and KLOOP are shown in Fig. 5. The stability of the $2.7 \mathrm{~kb}$ transcript and the $0.5 \mathrm{~kb}$ transcript in KLOOP decreased to approximately $75 \%$ and $60 \%$, respectively, of the wild-type values, whereas the stability of the $2.7 \mathrm{~kb}$ transcript and $0.5 \mathrm{~kb}$ transcript in $\Delta \mathrm{K}$ increased approximately $25 \%$ and $140 \%$, respectively, compared with those from the wild-type. Thus, substantial structural alteration of the $5^{\prime}$ region within $p u f K$ had a significant effect on the stability of both $p u f$-specific transcripts.

\section{DISCUSSION}

First, and most importantly, all of the available evidence indicates that $p u f K$ can be translated in vivo and that either the frequency of occurrence of rare codons in $p u f K$, their absolute numbers, their absolute identity or any combination of such factors can influence translation through $p u f K$. Most noteworthy is the asymmetrical distribution of these codons, in the proximal and distal portions of pufK (Fig. 1). We reason that slowing of translation early and then later through $p u f K$, because of its small size, causes a pileup of ribosome(s), resulting in a blockage of translation initiation at $p u f K$. This second point gains some support from the observation that in the MAE mutant by relieving the distal blockage in pufK we may increase ribosome movement through the proximal region of $p u f K$, thus we increase expression from $p u f K$ by a factor of 10-13, with similar increases observed for cells grown either aerobically or photosynthetically. This level of translation through pufK in the MAE mutant is nearly identical to that observed for the $p u f B$ : : lac $Z$ fusion in the wild-type.

It appears that the ultimate cellular level of the B875 complex or the individual polypeptide(s) comprising this complex can vary quite independently of the ultimate cellular levels of the cognate mRNA species. Therefore, mRNA levels and the half-lives of these mRNAs do not appear to be, within the boundaries reported here, a major factor in determining the final level of the B875 complex. From the levels of B800-850 it appears that pigments are not a limiting factor. Thus, translational control of spectral complex formation appears to be a major factor in determining the final cellular content of the $\mathrm{B} 875$ complex as well as the B800-850 complex. Because these experiments are performed in photosynthetically growing cells we cannot make such a statement regarding the $\mathrm{RC}$, although we have previously shown that the RC-H polypeptide may be important in RC formation (Sockett et al., 1988; Varga \& Kaplan, 1993).

Nucleotide sequence analysis revealed that the $p u f K$ translation stop codon and $p u f B$ start codon are separated by one base, UAG-C-AUG. Additionally, the putative pufB S-D sequence, GGAGG, is located entirely within the $p u f K$ coding region, suggesting that the two genes are translationally coupled. Translational coupling has been reported for a number of gene pairs, including galK-galT (Schümperli et al., 1982), trpD-trpE (Oppenheim \&

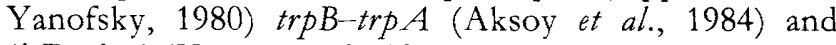
$i l v D$-ilv $A$ (Harms et al., 1988). In these systems, translationally coupled genes are either separated by intercistronic regions which are less than three bases or they partially overlap.

The observation that the mutants KSD and KLOOP have little or no B875 complexes, or detectable B875 $\alpha$ polypeptide in the case of KLOOP, and yet grow either normally or near-normally under photosynthetic con- 


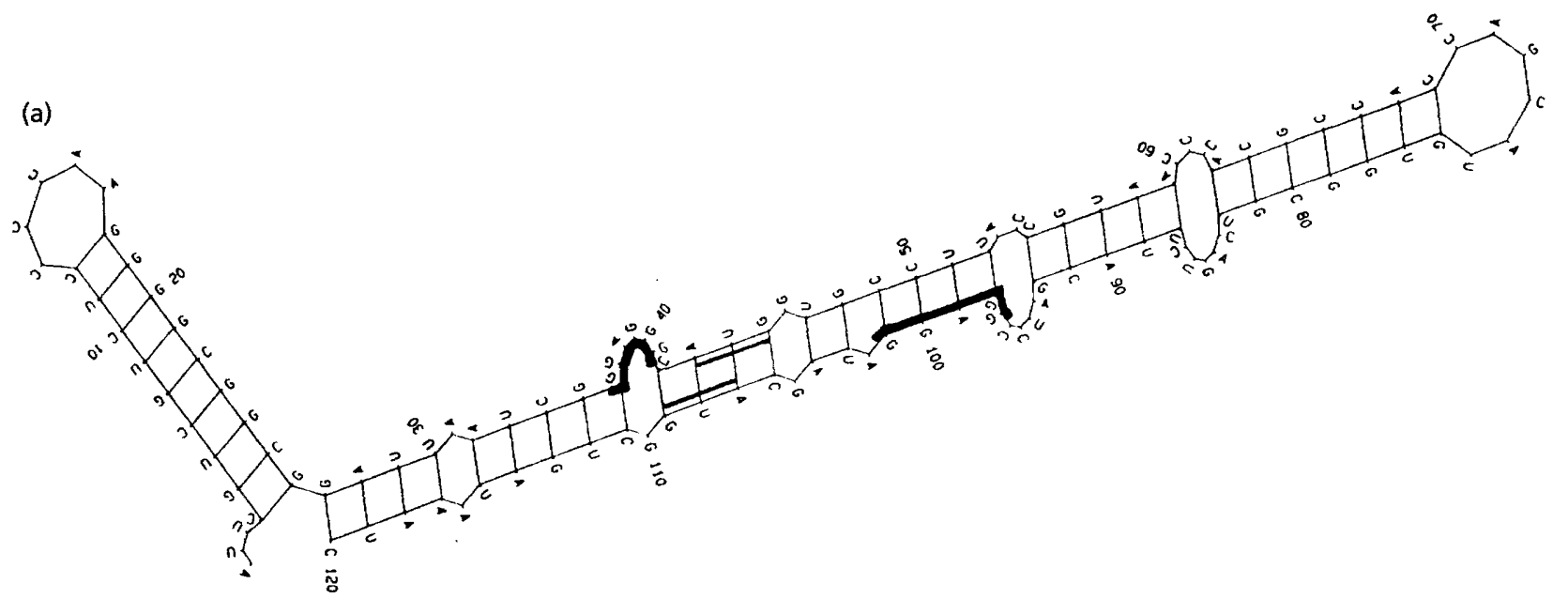

(b)

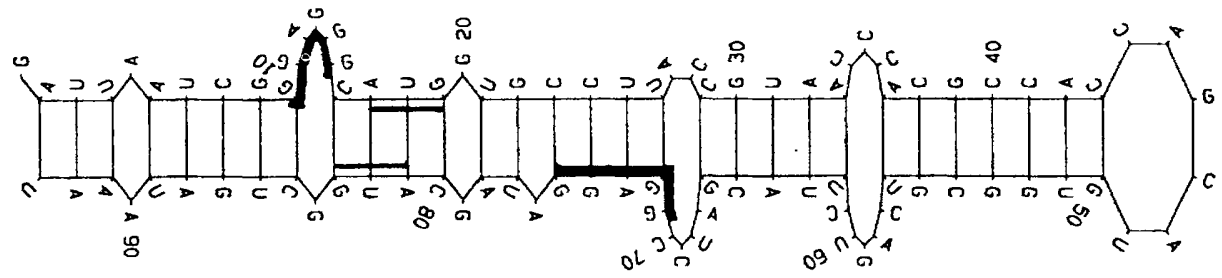

Fig. 6. Computer-predicted secondary structures of the $5^{\prime}$-terminal mRNA sequences specified by the small (0.5 kb) puf transcript (a) and the large $(2.7 \mathrm{~kb})$ puf transcript (b). The calculated $\Delta G$ for (a) (120 bases) is $-34.7 \mathrm{kcal}^{\mathrm{mol}}{ }^{-1}$ $\left(-145.2 \mathrm{~kJ} \mathrm{~mol}^{-1}\right)$. The calculated $\Delta G$ for (b) $\left(93\right.$ bases) is $-23.6 \mathrm{kcal} \mathrm{mol}^{-1}\left(-98.7 \mathrm{~kJ} \mathrm{~mol}^{-1}\right)$. The bold lines represent the ribosome-binding sites and the thin lines the initiation codons.

ditions implies that the level of RCs is normal or near normal. Therefore, it would follow that certain regions, i.e. pufL and pufM, of the large puf transcript in these mutants can be translated and perhaps other regions cannot. It has been demonstrated that eukaryotic ribosomes require at least 14 nucleotides upstream of the AUG codon for efficient translation initiation to occur (Sedman $t$ t al., 1990). The putative pufK S-D sequence is 9 and $34 \mathrm{nt}$ downstream of the $5^{\prime}$ end of the $2.7 \mathrm{~kb}$ and $0.5 \mathrm{~kb}$ puf transcripts, respectively. It may be that a ribosome cannot attach at the $\mathrm{S}-\mathrm{D}$ preceding pufK on the large $p u f$ transcript, but can initiate translation at the $S-D$ preceding $p u f K$ on the small transcript. Therefore, it is possible that the large $p u f$ transcript may not contribute to the production of either the B875 $\beta$ - or B875 $\alpha$ polypeptide. This conclusion gains some support from the fact that although in KSTART the level of the $0.5 \mathrm{~kb}$ transcript is reduced by $30 \%$, the level of $2.7 \mathrm{~kb}$ transcript is normal, yet the amount of B875 complex is reduced by approximately $40 \%$. Clearly, this observation is only consistent with this thesis and much more work is required. Nonetheless, it does provide an additional approach to viewing the derivation of these important polypeptides. Further, we suggest that the spacing and/or structure of the mRNA at the $5^{\prime}$ end of the small transcript is conducive to ribosome binding at $p u f K$ but that this is not the case for the large transcript. This is best illustrated in Fig. 6, which shows a computer generated representation of the $5^{\prime}$ region of the large and small puftranscripts. These computer-generated analyses of the puf transcripts predict that both the small and the large puf transcripts in 2.4.1 could, if $p u f K$ were not translated, form a stable secondary structure between the translation start sites (CAUG) of pufK and pufB (Fig. 6). These hypothetical turnstile structures would sequester the $S-D$ sequence of $p u f B$, requiring translation initiation of $p u f K$ for ribosomes to gain access to $p u f B$. Computer analysis of the $p u f$ mRNA in KLOOP (Fig. 7b) predicts the potential formation of an exaggerated RNA secondary structure near the translation initiation codon of $p u f B$, which could preclude translation of $p u f B$.

Thus, we suggest that translation through pufK, or ribosome association with $p u f K$, may be an important element in translation initiation at $p u f B$. This suggestion is supported by the data from mutants KSTART, KSD and KLOOP. Further, the fact that mutant MAE produces large amounts of apparently normal B875 further implies that de novo translation initiation can occur at $p u f B$ due to ribosome binding at $p u f K$ because initiation at $p u f K$ should produce a fusion protein of PufK and the B875 $\beta$ polypeptide. If such a protein is produced it must either be 
(a)

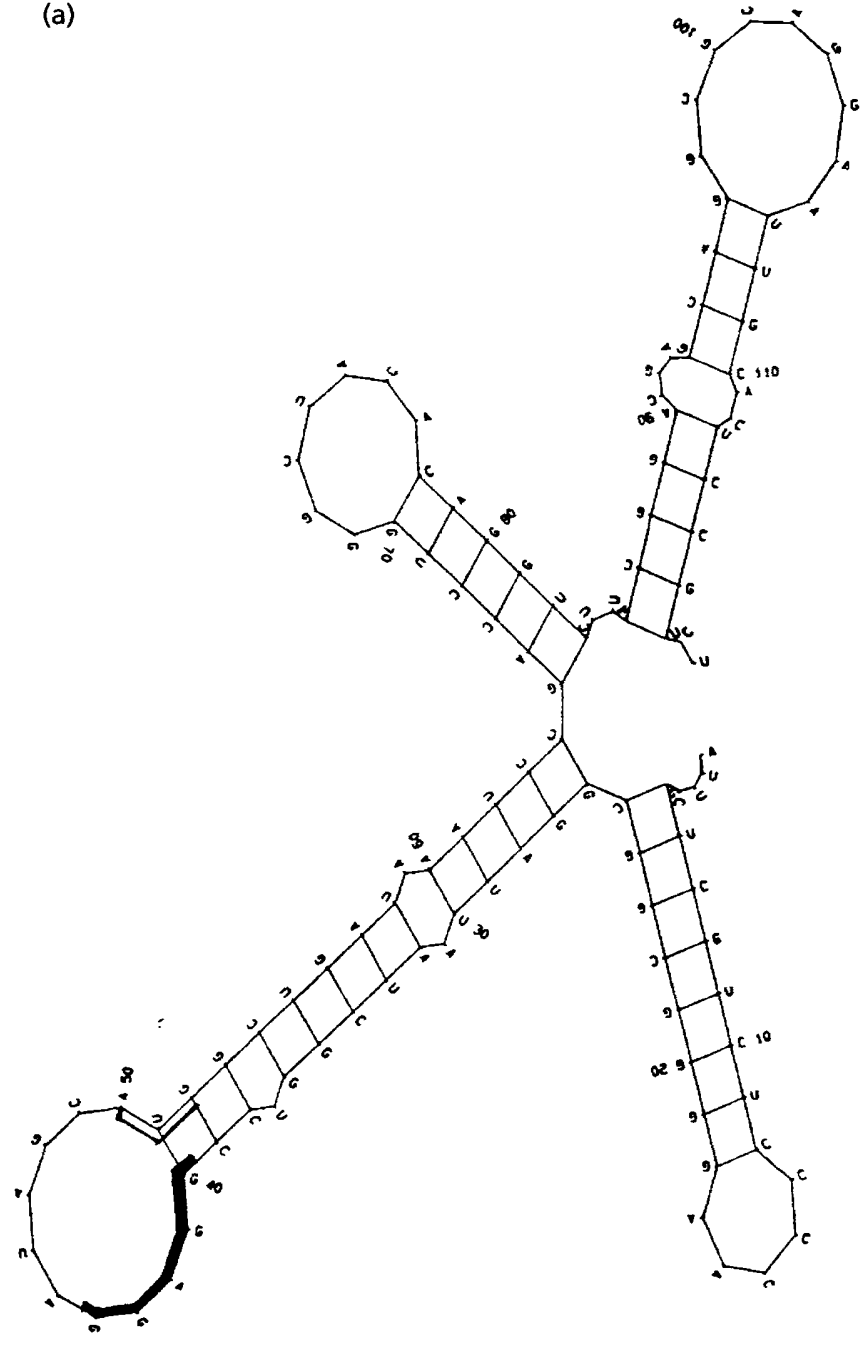

(b)

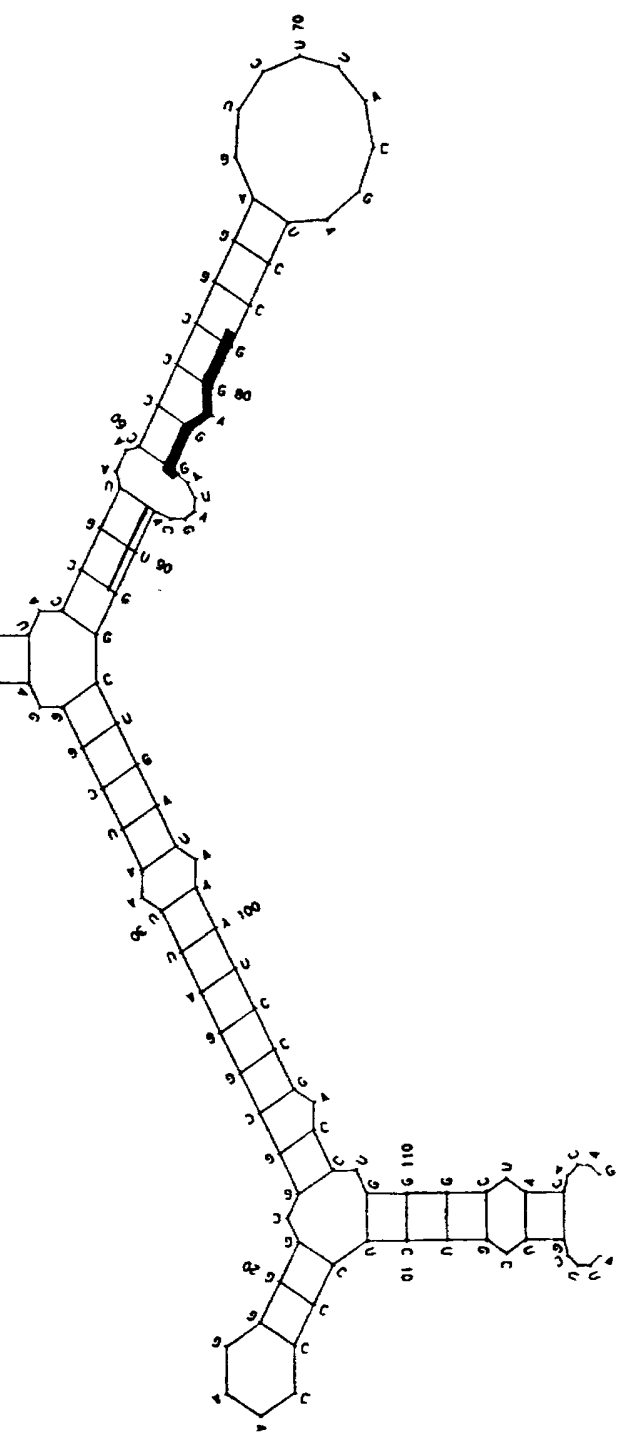

Fig. 7. Computer-predicted secondary structures of the 5 -terminal mRNA sequences specified by the small $(0.5 \mathrm{~kb})$ puf transcript from mutants $\Delta K$ (a) and KLOOP (b). The calculated $\Delta G$ for both (a) and (b) is $-34.9 \mathrm{kcal} \mathrm{mol}^{-1}$ $\left(-146.0 \mathrm{~kJ} \mathrm{~mol}^{-1}\right)$. The bold lines represent the ribosome-binding sites and the thin lines the initiation codons.

processed or broken down, because we could not observe any trace of it. If we examine the levels of the B875 spectral complexes in the wild-type and mutant strains and compare these levels to those of the B875 $\alpha$ polypeptide in the same strains we note that the level of the B875 $\alpha$-polypeptide must be in excess of the $\beta$ polypeptide as determined from the levels of the B875 complex, implying that translation of the $\alpha$-polypeptide can be dissociated from translation of the $\beta$-polypeptide. We make two assumptions which we believe to be reasonable, namely (i) in the wild-type the levels of $\beta$ - and $\alpha$-polypeptide are normally equal, and (ii) the cellular abundance of the B875 complex in the mutant strains is proportional to the abundance of the limiting polypeptide, when $\mathrm{Bchl}$ is plentiful, which appears to be the case here.

Examination of the data indicates that although there is no translation through $p u f K$ in KSTART, the level of the
B875 complex is $55 \%$ of that of wild-type, leading us to suggest that ribosomes can still associate with pufK, having an intact $\mathrm{S}-\mathrm{D}$ sequence and a suitable structure. In KLOOP we conclude that although the small puf mRNA level and/or stability is low relative to wild-type, it should be sufficient to produce both $\beta$ - and $\alpha$-polypeptides. Therefore we believe that the $0.5 \mathrm{~kb}$ puf mRNA secondary structure precludes association of ribosomes at either $p u f B$ or $p u f A$. The fact that these cells grow photosynthetically and contain no trace of B875 complexes provides some evidence that the large $p u f$ transcript can be used, but the small is not.

The significance of occurrence of ' rare' codons in mRNAs of regulatory and minor proteins has been studied previously (Farabaugh, 1978; Grantham et al., 1981; Grosjean \& Fiers, 1982; Stoner \& Schleif, 1982; Konigsberg \& Godson, 1983). It was proposed by Grosjean \& 
Fiers (1982) and by Gouy \& Gautier (1982) that rare codons might be translated more slowly. In this paper we have presented evidence for a mechanism dependent upon the presence of numerically unique and rare codons whose occurrence leads to, we believe, a pileup at translation initiation of $p u f K$, thereby leading to the accessibility of $p u f B$. The distance between the initiation sites for $p u f K$ and $p u f B$ would accommodate under three ribosomes. Codons with a third-position $\mathrm{A}$, where a pyrimidine residue could be used instead, are generally uncommon in Rhodobacter 'housekeeping' genes. Rhodobacter genes with CCA, TCA and TTA codons are extremely rare. Genes with TTA are also rare in Streptomyces, a genus of Grampositive bacteria with $\mathrm{G}+\mathrm{C}$-rich DNA (Leskiw et al., 1991); these genes mostly encode proteins needed only during morphological and physiological differentiation. Introduction of a TTA codon into a cloned heterologous gene was reported to dramatically reduce its expression in Streptomyces lividans (Leskiw et al., 1991). The case of KLOOP illustrates how these codons affect translation initiation. In the wild-type, $43 \%$ of the codons of pufK are rarely used, but in KLOOP approximately $53 \%$ of the codons are rare. Even allowing for the lower levels of the $0.5 \mathrm{~kb}$ puf transcript it appears that the higher frequency of rare codons in KLOOP results in a lower rate of protein synthesis. Importantly, the distribution of rare codons in $p u f K$ may be the most important feature in their regulation of $p u f B$ translation. These codons are concentrated at the $5^{\prime}$ and $3^{\prime}$ ends of pufK. Given the spacing required for a ribosome to attach, the pileup of ribosomes at the $5^{\prime}$ end of $p u f K$ will lead to translation of $p u f B$, whereas blockage at the $3^{\prime}$ end of puf $K$ will preclude translation of $p u f B$. Thus, it should be possible to easily regulate $p u f B$ expression through expression of $p u f K$. There is one report that the rare codon AGA at position 402 of the tolC mRNA in E. coli K12 halts translating ribosomes owing to a limitation in the amount of the tRNA $^{\text {Arg }}$ (AGA) species in the cell (Misra \& Reeves, 1985).

The results presented in this paper also show that there is a relationship between secondary structure at the $5^{\prime}$ end and mRNA stability. Recent studies have shown that a feature common to a number of long-lived prokaryotic messages is the potential to form a hairpin structure within 1-4 nucleotides of the $5^{\prime}$ end (Emory et al., 1992). Furthermore, a small number of $5^{\prime}$-terminal mRNA segments, such as the amp $A$ transcript of $E$. coli and the gene 32 message of phage $\mathrm{T} 4$, have been shown to stabilize heterologous messages to which they are fused (Emory et al., 1992). When a synthetic terminal hairpin was introduced at the $5^{\prime}$ terminus of the bla mRNA, the resulting bla 202 message was found to decay with a halflife of $6.8 \pm 0.4 \mathrm{~min}$, about twice the lifetime of wild-type bla mRNA (3.7 $\pm 0.3 \mathrm{~min}$; Von Gabain et al., 1983). The first 26 nucleotides of the small puf transcript may form a hairpin at the extreme $5^{\prime}$ terminus. In contrast, no such hairpin was predicted for the large $(2.7 \mathrm{~kb})$ puf transcript (Fig. 6b). These observations may help to explain why the half-life of the small puf transcript is twice $(22 \mathrm{~min})$ that of the large transcript $(10 \mathrm{~min})$.
$\Delta \mathrm{K}$ and KLOOP showed changes in the stability of the puf transcripts, whereas the mutations in KSTART, KSD and MAE had no effect on mRNA stability. A similar observation has been reported from the study of the PPR $1 \mathrm{mRNA}$ in Saccharomyces cerevisiae, in which the halflife can be extended by exchanging the 5'-UTR for that of the URA3 mRNA (Pierrat et al., 1993). These data exclude the possible involvement of the PufK peptide in mRNA stability, or for that matter in any obvious direct physiological role (Gong et al., 1994). A recent paper by Gish \& Yanofsky (1995), studying the role of the small leader peptide in regulating the expression of the downstream tryptophanase gene of $E$. coli, suggests that this peptide may act at the translational/post-transcriptional level only when produced in cis. Thus, through the use of rare codons and their placement within pufK, $R$. sphaeroides may be able to regulate downstream gene expression through a translation-attenuation-like mechanism. What is clear, is that translation of the $0.5 \mathrm{~kb} p u f$ mRNA is not required to stabilize this mRNA; a similar conclusion was reached by Klug \& Cohen (1991). $\Delta \mathrm{K}$ produces little or no B875 complex and therefore little or no $\beta$-peptide, yet the half-life of its $0.5 \mathrm{~kb}$ transcript is $140 \%$ greater than the wild-type.

In summary, our data demonstrate that $p u f K$ is translated and that the occurrence of rare codons influences the rate of translation. Translation of $p u f B$ appears to be dependent upon translation of $p u f K$. We additionally confirm previous observations that the levels of mRNA encoding the structural polypeptides of the LH complexes are in variably in excess of cellular needs. Data were also interpreted to suggest that only the small puf transcript is involved in the synthesis of the $\beta$ - and $\alpha$-polypeptides of the B875 complex. Finally, the secondary structure at the $5^{\prime}$ end of the large and small puf transcripts strongly influences mRNA stability and accessibility to the $p u f K$ $\mathrm{S}-\mathrm{D}$ and therefore the translation of $p u f B$.

\section{ACKNOWLEDGEMENTS}

We are grateful to Robert Gould for contributing to the early stages of this work and D. Needleman and X. Y. Wang for performing automated DNA sequencing. L.G. also thanks J. K. Lee, J. M. Eraso, M. Gomelsky, J. Zeilstra-Ryalls and A. Yeliseev for stimulating discussions.

This work was supported by Public Health Service grant GM 15590 to S.K. from the National Institutes of Health.

\section{REFERENCES}

Aksoy, S., Squires, C. L. \& Squires, C. (1984). Translational coupling of the $\operatorname{trp} B$ and $\operatorname{trp} A$ genes in the Eschericbia coli tryptophan operon. $J$ Bacteriol 157, 363-367.

Barz, W. P. \& Oesterhelt, D. (1994). Photosynthetic deficiency of a puf $X$ deletion mutant of Rhodobacter sphaeroides is suppressed by point mutations in the light-harvesting complex genes $p u f B$ or puf A. Biochemistry 33, 9741-9742.

Belasco, J. G., Beatty, J. T., Adams, C. W., Gabian, A. v. \& Cohen, S. N. (1985). Differential expression of photosynthesis genes in $R$. 
capsulata results from segmental differences in stability within the polycistronic $r \times c A$ transcript. Cell 40, 171-181.

Davis, J., Donohue, T. J. \& Kaplan, S. (1988). Construction, characterization, and complementation of a $\mathrm{Puf}^{-}$mutant of Rhodobacter sphaeroides. J Bacteriol 170, 320-329.

DeHoff, B. S., Lee, J. K., Donohue, T. J., Gumport, R. I. \& Kaplan, S. (1988). In vivo analysis of puf operon expression in Rhodobacter sphaeroides after deletion of a putative intercistronic transcription terminator. J Bacteriol 170, 4681-4692.

Dryden, S. C. \& Kaplan, S. (1990). Location and structural analysis of the ribosomal RNA operons of Rhodobacter spbaeroides. Nucleic Acids Res 18, 7267-7277.

Dubnau, D. (1984). Translational attenuation: the regulation of bacterial resistance to the macrolide-lincosamide-stretogramin B antibiotics. Crit Rev Biochem 16, 103-132.

Emory, S. A., Bouvet, P. \& Belasco, J. G. (1992). A 5'-terminal stem-loop structure can stabilize mRNA in Escherichia coli. Genes Dev 6, 135-148.

Farabaugh, P. J. (1978). Sequence of the lacI gene. Nature 274, 765-769.

Farchaus, J. W., Barz, W. P., Grunberg, H. \& Oesterhelt, D. (1992). Studies on the expression of the pufX polypeptide and its requirement for photoheterotrophic growth in Rhodobacter sphaeroides. EMBO J 11, 2779-2788.

Gish, K. \& Yanofsky, C. (1995). Evidence suggesting cis action by the $\mathrm{TnaC}$ leader peptide in regulating transcription attenuation in the tryptophanase operon of Escherichia coli. $J$ Bacteriol 177, 7245-7254.

Gold, L. \& Stormo, G. (1987). Translational initiation. In Escherichia coli and Salmonella typhimurium: Cellular and Molecular Biology, pp. 1302-1307. Edited by F. C. Neidhardt, J. L. Ingraham, K. Brooks Low, B. Magasanik, M. Schaechter \& H. E. Umbarger. Washington, DC: American Society for Microbiology.

Gong, L., Lee, J. K. \& Kaplan, S. (1994). The $Q$ gene of Rhodobacter sphaeroides: its role in puf operon expression and spectral complex assembly. J Bacteriol 176, 2946-2961.

Gouy, M. \& Gautier, C. (1982). Codon usage in bacteria : correlation with gene expressivity. Nucleic Acids Res 10, 7055-7074.

Grantham, R., Gautier, C., Gouy, M., Jacobzone, M. \& Mercier, R. (1981). Codon catalog usage is a genome strategy modulated for gene expressivity. Nucleic Acids Res 9, 243-274.

Grosjean, H. \& Fiers, W. (1982). Preferential codon usage in prokaryotic genes: the optimal codon-anticodon interaction energy and the selective codon usage in efficiently expressed genes. Gene 18, 199-209.

Harms, E., Higgins, E., Chen, I.-J. W. \& Umbarger, H. E. (1988). Translational coupling between the $i l v D$ and $i l v A$ genes of Escherichia coli. J Bacteriol 170, 4798-4807.

Hess, S., Visscher, K., Ulander, J., Pullerits, T., Jones, M. R., Hunter, C. N. \& Sundström, V. (1993). Direct energy transfer from the peripheral LH2 antenna to the reaction center in a mutant of Rhodobacter sphaeroides that lacks the core LHI antenna. Biochemistry 32, 10314-10322.

Horinouchi, S. \& Weisblum, B. (1980). Post-transcriptional modification of mRNA conformation: mechanism that regulates erythromycin-induced resistance. Proc Natl Acad Sci US A 77, 7079-7083.

Keen, N. T., Tamaki, S., Kobayashi, D. \& Trollinger, D. (1988). Improved broad-host-range plasmids for DNA cloning in Gramnegative bacteria. Gene 70, 191-197.

Kiley, P. J. \& Kaplan, S. (1988). Molecular genetics of photosyn- thetic membrane biosynthesis in Rhodobacter sphaeroides. Microbiol Rev 52, 50-69.

Kiley, P. J., Donohue, T. J., Havelka, W. A. \& Kaplan, S. (1987). DNA sequence and in vitro expression of the B875 light-harvesting polypeptides of Rhodobacter sphaeroides. J Bacteriol 169, 742-750.

Klug, G. \& Cohen, S. N. (1991). Effects of translation on degradation of mRNA segments transcribed from the polycistronic puf operon of Rhodobacter capsulatus. J Bacteriol 173, 1478-1484.

Klug, G., Adams, C. W., Belasco, J., Doerege, B. \& Cohen, S. N. (1987). Biological consequences of segmental alterations in mRNA stability : effects of deletion of the intercistronic hairpin loop region of the Rhodobacter capsulatus puf operon. EMBO J 6, 3515-3520.

Konigsberg, W. \& Godson, G. N. (1983). Evidence for use of rare codons in the $d n a G$ gene and other regulatory genes of Escherichia coli. Proc Natl Acad Sci US A 80, 687-691.

Kordes, E., Jack, S., Fritsch, J., Bosch, J. F. \& Klug, G. (1994). Cloning of a gene involved in rRNA precursor processing and 23S rRNA cleavage in Rbodobacter capsulatus. J Bacteriol 176, 1121-1127.

Lee, J. K., DeHoff, B. S., Donohue, T. J., Gumport, R. I. \& Kaplan, S. (1989). Transcriptional analysis of puf operon expression in Rhodobacter sphaeroides 2.4 .1 and an intercistronic transcription terminator mutant. J Biol Chem 264, 19354-19365.

Leskiw, B. K., Bibb, M. J. \& Chater, K. F. (1991). The use of a rare codon specifically during development? Mol Microbiol 5, 2861-2867.

Little, S., Hyde, S., Campbell, C. J., Lilley, R. J. \& Robinson, M. K. (1989). Translational coupling in the threonine operon of Escherichia coli K-12. J Bacteriol 171, 3518-3522.

McGlynn, P., Hunter, C. N. \& Jones, M. R. (1994). The Rhodobacter sphaeroides PufX protein is not required for photosynthetic competence in the absence of a light harvesting system. FEBS Lett 349 , 349-353.

Meinhardt, S. W., Kiley, P. J., Kaplan, S., Crofts, A. R. \& Harayama, S. (1985). Characterization of light-harvesting mutants of Rhodopseudomonas sphaeroides. I. Measurement of the efficiency of energy transfer from light-harvesting complexes to the reaction center. Arch Biochem Biophys 236, 130-139.

Misra, R. \& Reeves, P. (1985). Intermediates in the synthesis of TolC protein include an incomplete peptide stalled at a rare Arg codon. Eur J Biochem 152, 151-155.

Neidle, E. L. \& Kaplan, S. (1992). 5-Aminolevulinic acid availability and control of spectral complex formation in HemA and HemT mutants of Rhodobacter sphaeroides. J Bacteiol 175, 6444-6454.

Neidle, E. L. \& Kaplan, S. (1993). Expression of the Rhodobacter sphaeroides bem $A$ and bem $T$ genes, encoding two 5-aminolevulinic acid synthase isozymes. J Bacteriol 175, 2292-2303.

Oppenheim, D. \& Yanofsky, C. (1980). Translational coupling during expression of the tryptophan operon in Escherichia coli. Genetics 95, 785-795.

Pierrat, B., Lacroute, F. \& Losson, R. (1993). The $5^{\prime}$ untranslated region of the PPR1 regulatory gene dictates rapid mRNA decay in yeast. Gene 131, 43-51.

Riggs, D. \& Artz, S. (1984). The bisD-bis $C$ gene border of the Salmonella typhimurium histidine operon. Mol Gen Genet 196, 526-529.

Sambrook, J., Fritsch, E. F. \& Maniatis, T. (1989). Molecular Cloning: a Laboratory Manual. Cold Spring Harbor, NY: Cold Spring Harbor Laboratory.

Sanger, F., Nicklen, S. \& Coulson, A. R. (1977). DNA sequencing with chain-terminating inhibitors. Proc Natl Acad Sci USA 74, $5463-5467$. 
Schümperli, D., Mckenny, K., Sobieski, D. A. \& Rosenberg, M. (1982). Translational coupling at an intercistronic boundary of the Eschericbia coli galactose operon. Cell 30, 865-871.

Sedman, S. A., Gelembiuk, G. W. \& Mertz, J. E. (1990). Translation initiation at a downstream $A U G$ occurs with increased efficiency when the upstream AUG is located very close to the $5^{\prime}$ cap. J Virol 64, 453-457.

Simon, R., Priefer, U. \& Puhler, A. (1983). A broad host range mobilization system for in vivo genetic engineering: transposon mutagenesis in Gram-negative bacteria. Bio/Technology 1, 37-45.

Sistrom, W. R. (1962). The kinetics of the synthesis of photopigments in Rhodopseudomonas sphaeroides. J Gen Microbiol 28, 607-616.

Sockett, R. E., Donohue, T. J., Varga, A. R. \& Kaplan, S. (1988). Control of photosynthetic membrane assembly in Rhodobacter sphaeroides mediated by puh. $A$ and flanking sequences. $J$ Bacteriol 171, 436-446.

Sprengel, R., Reiss, B. \& Schaller, H. (1985). Translationally coupled initiation of protein synthesis in Bacillus subtilis. Nucleic Acids Res 13, 893-909.

Stoner, C. M. \& Schleif, R. F. (1982). Is the amino acid but not the nucleotide sequence of the Escherichia coli araC gene conserved? J Mol Biol 154, 649-652.
Tai, T. N., Havelka, W. A. \& Kaplan, S. (1988). A broad-host-range vector system for cloning and translational lac $Z$ fusion analysis. Plasmid 19, 175-188.

Tichy, H. V., Oberle, B., Stiehle, H., Schiltz, E. \& Drews, G. (1989). Genes downstream from $p u c B$ and $p u c A$ are essential for formation of the B800-850 complex of Rbodobacter capsulatus. J Bacteriol 171, 4914-4922.

Van Niel, C. B. (1944). The culture, general physiology, morphology and classification of the non-sulfur purple and brown bacteria. Bacteriol Rev 8, 1-118.

Varga, A. R. \& Kaplan, S. (1993). Synthesis and stability of reaction center polypeptides and implications for reaction center assembly in Rhodobacter sphaeroides. J Biol Chem 26, 19842-19850.

Von Gabain, A., Belasco, J. G., Schottel, J. L., Chang, A. C. \& Cohen, S. N. (1983). Decay of mRNA in Escherichia coli: investigation of the fate of specific segments of transcripts. Proc Natl Acad Sci US A 80, 653-657.

Zhu, Y. S., Kiley, P. J., Donohue, T. J. \& Kaplan, S. (1986). Origin of the mRNA stoichiometry of the puf operon in Rbodobacter sphaeroides. J Biol Chem 261, 10366-10374.

Received 22 January 1996; revised 14 March 1996; accepted 19 March 1996. 